\title{
Microsporidia-like parasites of amoebae belong to the early fungal lineage Rozellomycota
}

\author{
Daniele Corsaro • Julia Walochnik • Danielle Venditti • \\ Jörg Steinmann • Karl-Dieter Müller • Rolf Michel
}

Received: 9 October 2013 / Accepted: 24 February 2014 / Published online: 21 March 2014

(C) Springer-Verlag Berlin Heidelberg 2014

\begin{abstract}
Molecular phylogenies based on the small subunit ribosomal RNA gene (SSU or 18S ribosomal DNA (rDNA)) revealed recently the existence of a relatively large and widespread group of eukaryotes, branching at the base of the fungal tree. This group, comprising almost exclusively environmental clones, includes the endoparasitic chytrid Rozella as the unique known representative. Rozella emerged as the first fungal lineage in molecular phylogenies and as the sister group of the Microsporidia. Here we report rDNA molecular phylogenetic analyses of two endonuclear parasites of free-
\end{abstract}

Electronic supplementary material The online version of this article (doi:10.1007/s00436-014-3838-4) contains supplementary material, which is available to authorized users.

D. Corsaro $(\triangle) \cdot$ D. Venditti

CHLAREAS - Chlamydia Research Association, Nancy, 12 rue du Maconnais, 54500 Vandœuvre-lès-Nancy, France

e-mail: corsaro@voila.fr

D. Corsaro

Laboratory of Soil Biology, University of Neuchâtel, rue Emile Argand 11, Neuchâtel 2000, Switzerland

J. Walochnik

Molecular Parasitology, Institute of Specific Prophylaxis and

Tropical Medicine, Medical University of Vienna, Kinderspitalgasse

15, 1090 Vienna, Austria

D. Venditti

Tredi Research Department, Faculty of Medicine, Technopôle de

Nancy-Brabois, 9, Avenue de la Forêt de Haye, B.P. 184,

54505 Vandœuvre-lès-Nancy, France

J. Steinmann · K.-D. Müller

Institut of Medical Microbiology, University of Duisburg-Essen,

Virchowstr.179, 45147 Essen, Germany

\section{R. Michel}

Laboratory of Medical Parasitology, Central Institute of the Federal Armed Forces Medical Services, P.O. Box 7340, 56070 Koblenz, Germany living naked amoebae having microsporidia-like ultrastructural features but belonging to the rozellids. Similar to microsporidia, these endoparasites form unflagellated walled spores and grow inside the host cells as unwalled nonphagotrophic meronts. Our endonuclear parasites are microsporidia-like rozellids, for which we propose the name Paramicrosporidium, appearing to be the until now lacking morphological missing link between Fungi and Microsporidia. These features contrast with the recent description of the rozellids as an intermediate wall-less lineage of organisms between protists and true Fungi. We thus reconsider the rozellid clade as the most basal fungal lineage, naming it Rozellomycota.

Keywords Microsporidia $\cdot$ Rozellomycota $\cdot$

Paramicrosporidium $\cdot$ Chytrids $\cdot$ Amoebae $\cdot$ Endoparasite

\section{Introduction}

Microsporidia are peculiar organisms having developed unique morphological and genomic adaptations to intracellular parasitism (Vávra and Lukeš 2013). Their life cycle includes an infectious spore, the content of which (sporoplasm) is injected into the host cell through a polar filament (Franzen 2004). Then the parasite proliferates as meronts by repeated fissions (merogony) and finally develops into sporonts (sporogony) forming organelles and walls to produce mature spores. Microsporidia have also greatly modified the nuclear genome and reduced mitochondria to mitosomes (Vávra and Lukeš 2013).

Microsporidia are major animal parasites, mainly of invertebrates, acquiring increasing importance in human infections (Didier and Weiss 2011). They are rarely reported among protists only in Alveolata, i.e., ciliates and gregarines, but not in amoebae (Canning and Vávra 2000; Vávra and Lukeš 
2013; Fokin et al. 2008). Morphology and molecular analyses showed that ciliate parasites belong to the large group of classic microsporidia (Foissner and Foissner 2005; Fokin et al. 2008), while morphology suggests that metchnikovellids, hyperparasites of gregarines, form a distinct, likely basal group, the Rudimicrosporea (Sprague 1977; Larsson and Køie 2006; Sokolova et al. 2013).

The morphological and genetic uniqueness of Microsporidia led to their consideration as a separate group with an enigmatic origin, only recently recognized as related to Fungi (Vávra and Lukeš 2013). An evolutionary link between Fungi and Microsporidia was indeed suggested by using various protein-coding genes, obtaining however different results (Corradi and Keeling 2009). Recent phylogenomic studies rejected the zygomycete ancestry suggesting an early emergence of Microsporidia (Koestler and Ebersberger 2011; Capella-Gutiérrez et al. 2012) and even supported the basal position and the sister group relationship between Microsporidia and the endoparasitic chytrid Rozella allomycis (James et al. 2013), already suggested (James et al. 2006a) by sequence data of the RNA polymerase II genes (RPB1 and RPB2). RPBs and ribosomal DNA (rDNA) phylogenies supported also the close relationship of the Aphelidea, a poorly known group of endoparasites of algae, proposing the ARM (Aphelids-Rozella-Microsporidia) clade (Karpov et al. 2013; Letcher et al. 2013).

Rozella spp. are unicellular endoparasites of other chytrids, algae, and oomycetes (Held 1981), considered the most basal clade of the Fungi (James et al. 2006a, b). Like other chytrids, Rozella have uniflagellate unwalled zoospores. These encyst on the host surface and form a penetration tube to infect the host cell. Rozella are peculiar because they grow intracellularly as a wall-less thallus, they have zoosporangia with thick walls acquired from the host cells (Held 1981), and some species seem to be able to phagocytize host organelles (Powell 1984). Recent works however showed that Rozella is able to produce a chitinous wall in both immature resting spores and cysts (James and Berbee 2012; James et al. 2013). Molecular phylogenetic analyses have shown that Rozella belongs to a larger group of uncultured environmental clones, mainly from freshwater biotopes, named Rozellida (Lara et al. 2010). Using a combination of molecular and staining methods, Jones et al. (2011a) showed that members of this clade, renamed Cryptomycota (Jones et al. 2011b), are wallless chytrid-like organisms, having flagellated zoospores and unwalled epibiont cells and cysts.

We previously reported on endonuclear microsporidia-like organisms infecting amoebae (Amoebozoa) isolated from environmental (Hoffmann et al. 1998; Michel et al. 2009; 2012) and clinical (Michel et al. 2000) samples. These organisms all show similar ultrastructural and developmental features, but can be clearly distinguished by their irregularly coiled polar filaments differing from both the short manubrium of metchnikovellids (Sprague 1977) and the regularly coiled or rarely uncoiled filament of microsporidia (Canning and Vávra 2000).

Our study focuses on the molecular phylogenetic analyses of these endoparasites. We demonstrate herein that these endoparasites are additional members of rozellids having striking ultrastructural resemblance with Microsporidia. Our results highlight the need for a redefinition of the rozellids and open new evolutionary perspectives to elucidate the origin and evolution of the Microsporidia.

\section{Materials and methods}

Strains origin and culture

Strains KAUN and KSL3 infected Vannella sp. and Saccamoeba sp., respectively, isolated from a keratitis patient (Michel et al. 2000) and a freshwater pond (Michel et al. 2009). The strain KW19, infecting a tap water Vannella sp. (Hoffmann et al. 1998), was lost during coculture. Endoparasites were grown in their respective host amoebae at room temperature on bacterized $1.5 \%$ nonnutritive agar as described (Hoffmann et al. 1998; Michel et al. 2000, 2009) and recovered by filtration through $2-, 1.2-$, and $0.5-\mu \mathrm{m}$ membranes. The $18 \mathrm{~S}$ rDNA was amplified and sequenced by using a set of eukaryotic primers (López-García et al. 2001; Corsaro et al. 2013) in different combinations: $42 \mathrm{~F}$ (5'-CTCAARGAYTAAGCCATGCA-3'), 82 F (5'-GAAACT GCGAATGGCTC-3'), 1498R (5'-CACCTACGGAAACCTT GTTA-3'), 1520R (5'-CYGCAGGTTCACCTA-3'), 6 F (5'CCAGCTCYAAKAGCGTATATT-3'), and 9R (5'-GTTGAG TCRAATTAAGCCGC-3'). The primers $6 \mathrm{~F}, 1520 \mathrm{~F}\left(5^{\prime}\right.$ GTAGGTGAACCTGCRG-3') and 28S-564R (5'-TGGTCC GTGTTTCRAGACG-3') were used to complete the rDNA unit for the strain KSL3, including $18 \mathrm{~S}$, 5.8S, partial $28 \mathrm{~S}$ (LSU), and both first and second internal transcribed spacers (ITS1 and ITS2).

The presence of a chitin/cellulose cell wall of endoparasites was shown by using Calcofluor White (Becton \& Dickinson) according to the manufacturer's instructions. Electron microscopy was performed as described (Hoffmann et al. 1998; Michel et al. 2000, 2009).

Phylogenetic analysis

The SSU rDNA sequences were aligned using MUSCLE at the European Bioinformatics Institute website www.ebi.ac.uk, thus manually refined using BIOEDIT. Phylogenies were calculated using MrBayes (Ronquist and Huelsenbeck 2003) , for $25 \times 10^{6}$ generations, sampling every 500 generations, and maximum likelihood (ML, GTR, $\Gamma+\mathrm{I}: 4$ model) with Treefinder (Jobb et al. 2004), with 1,000 bootstraps. The list 
of taxa with their GenBank accession numbers is provided in Supplementary Table 1. We retrieved from GenBank rDNA units for representatives of main groups of Fungi and relatives. Thus, ITS regions were excluded, and the three ribosomal genes were separately aligned with MUSCLE. Concatenated sequences were realigned and manually refined using BIOEDIT, and maximum likelihood phylogeny was carried out as described. Bootstrap values (1,000 replicates) were estimated for maximum likelihood (Jobb et al. 2004) and maximum parsimony and minimum evolution trees (Tamura et al. 2011) under substitution models G:4 and G:6, with heterogeneous patterns among lineages. Neighbor joining (G:4 model, 1,000 replicates) produced a tree topology identical to that obtained with minimum evolution (not shown).

Fluorescence in situ hybridization (FISH)

Infected amoebae were harvested from agar plates onto a slide in distilled water. Fixation, drying and partial lysis of the cells was performed by using a commercially available kit according to the manufacturer's instructions (miacom diagnostics, Duesseldorf, Germany). A solution of the fluorophore-labeled (ATTO500) molecular DNA beacons was added using one oligonucleotide probe, specific for either KSL3 (TGACTCAC CAAAAGCACGAG), or for eukaryote 18S rDNA (CGCG GTCTCAGGCTCCCTCTCCCCGCG).

\section{ITS2 analysis}

ITS2 sequences for KSL3, Rozella spp., and WS-CM2 were delimited using the online annotation tool (http://its2.bioapps. biozentrum.uni-wuerzburg.de/cgi-bin/index.pl?annotator) under the following parameters: model (Fungi), maximum $E$ values $(E<1.0)$, and minimum size of ITS2 (100 nt). Secondary structures were inferred using Mfold (http://mfod. bioinfo.rpi.edu/cgi-bin/rna-form1.cgi).

\section{Results and discussion}

\section{Morphological features}

The microsporidia-like morphology of our endoparasites has been previously described (Hoffmann et al. 1998; Michel et al. 2000, 2009). We confirm herein these data, coupling with molecular ones, providing a global interpretation. Our strains show proliferative pleomorphic merogonic stages (Fig. 1b, d) occurring within the nucleus of amoebae hosts, from which sporoblasts originate showing development of organelles. Mature spores accumulate in a dilated amoeba nucleus (Fig. 1a) before their release after amoebal lysis; they are ovoidal/coccoidal, $1.0-1.20 \times 0.8-1.0 \mu \mathrm{m}$, without flagellum, with clear endospore and exospore walls, a single prominent nucleus, and electron-dense structures interpreted as possible anchoring discs (Fig. 1c).

Other traits shared with microsporidia are the presence of a chitin/cellulose cell wall as indicated by calcofluor white staining (Supplementary Fig. 1a), the absence of a flagellated stage, and the lack of mitochondria. By contrast, spores invade amoebae through host phagocytosis reaching the amoeba nucleus without activation of polar tubes (Michel et al. 2000, 2009; Scheid 2007; this study). Indeed, in Microsporidia, the polar tube is rapidly extruded to pierce the host cell membrane (Franzen 2004; Vávra and Lukeš 2013).

\section{Molecular phylogeny}

Our previous trials with microsporidia-specific primers failed. To elucidate the phylogenetic position of these parasites, we thus performed 18S rDNA amplification and sequencing of two strains (KAUN and KSL3), by using eukaryotic-specific primers. Specific and eukaryotic probes were used to detect endoparasites in hospite by FISH (Supplementary Fig. 1b).

Our 18S rDNA phylogenetic analysis (Fig. 2) is largely congruent with previous results (James et al. 2006a; Shalchian-Tabrizi et al. 2008; Liu et al. 2009). Choanozoa (sensu Cavalier-Smith) are paraphyletic, with Nucleariidae sister to Fungi (clade holomycota), and other lineages clustering with animals (clade holozoa). The kingdom Fungi is well supported (Bayesian and maximum likelihood values $1 / 85 \%$ ), as well as the major chytrid phyla, and Glomeromycota emerges as sister to Dikarya (Ascomycota+ Basidiomycota). Both our strains branch close to each other (93.8\% sequence identity), within a highly supported holophyletic clade, basal in the fungal tree, the Rozellida/ Cryptomycota, hereafter named Rozellomycota.

The overall $18 \mathrm{~S}$ tree topology is recovered by sampling much more taxa. By excluding Microsporidia, aphelids emerge as basal to Rozellomycota (Supplementary Fig. 2) (see also Karpov et al. 2013, Suppl. Fig. S4). By including Microsporidia, the three ARM group lineages cluster paraphyletically among them and other chytrids without support values (not shown) (see also Letcher et al. 2013, Suppl. Fig. S1).

By using all available primers, we failed to obtain RPB sequences from our strains. However, rDNA unit $(18 \mathrm{~S}+$ $5.8 \mathrm{~S}+28 \mathrm{~S}$ ) phylogeny further supports the basal position of aphelids and recovers a clade Rozellomycota + Microsporidia. In this analysis, Rozellomycota are paraphyletic, and one of our endoparasites emerges closer to holophyletic Microsporidia (Fig. 3). Furthermore, our endoparasite KSL3 also possesses the second internal transcribed spacer (ITS2), which separates the 5.8S from the 
Fig. 1 Ultrastructure of the amoebae endoparasites. a Overview of Saccamoeba with the nucleus filled by KSL3 spores $(s p)$. b Pleomorphic merogonic stages $(P)$ within the amoeba nucleus. Nuclear host membrane (white arrows) remains intact. c Ultrastructure of KSL3 spore. Rounded or ovoidal spores inside the karyoplasm, showing exospore $(e x)$ and endospore (en) layers, a prominent nucleus $(N)$, and internal structures interpreted as anchoring disc $(a d)$ and irregular coiled polar filament $(p f)$. d Two spores of KAUN inside separate cytoplasmic vacuoles of Vannella, migrating toward the host nucleus (arrows point to nuclear membrane); a developing pleomorphic parasite $(P)$ is visible in the host nucleus. e Spores of KW19 from Vannella. Scale bars $=2 \mu \mathrm{m}(\mathbf{a}, \mathbf{b}) ; 1 \mu \mathrm{m}(\mathbf{c}-\mathbf{e})$
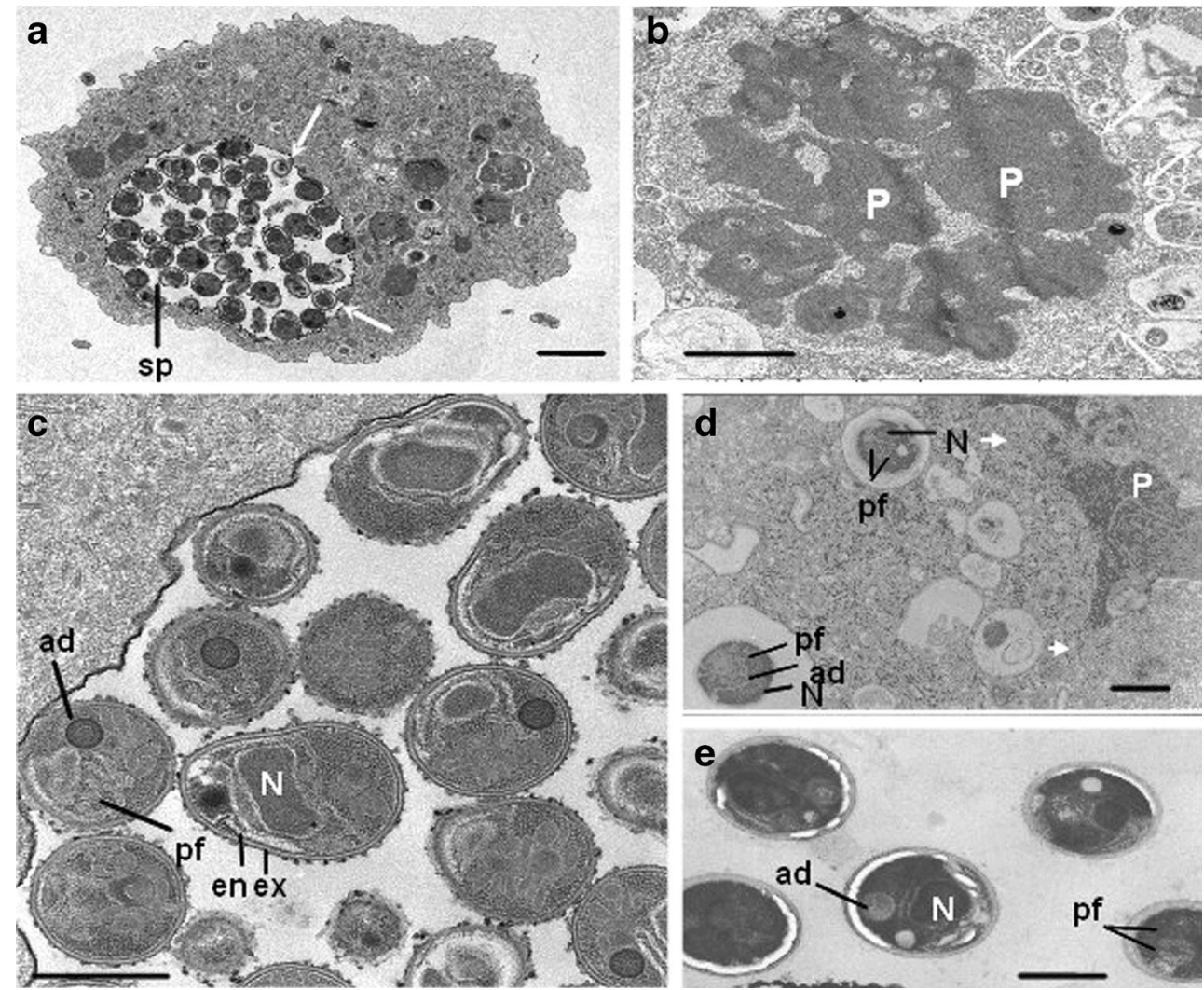

28S. This corresponds to the usual rRNA gene structure of the eukaryotes, with the notable exception of the Microsporidia, which lack the ITS2 and usually have the 5.8S fused into the LSU (Torres-Machorro et al. 2010; Vávra and Lukeš 2013) (ESM, Supplementary Table 2, Supplementary Fig. 3).

\section{Proposal of Paramicrosporidium gen. nov}

The endoparasites reported herein, recovered from different hosts, constitute distinct phylotypes with a virtually identical morphotype (Fig. 1), resembling most Microsporidia, not chytrids. Molecular phylogenies (Figs. 2 and 3) demonstrate that they are actually members of Rozellomycota possibly related to Microsporidia. On the basis of $18 \mathrm{~S}$ rDNA similarity values, our strains are relatively distant from $R$. allomycis and Rozella sp. JEL347 ( 85\%) and slightly closer each other ( $\sim 94 \%$ ) than the two Rozella spp. ( $\sim 91 \%)$. Thus, we consider them as belonging to closely related species of the same new genus.

Previously, the name Amoebosporidium was proposed for another of these strains, as morphology suggested a new microsporidian genus (Hoffmann et al. 1998). However, this name revealed to have been used in the late nineteenth century to describe different sporozoans, e.g., the subclass "Amoebosporidia Schneider 1884," later renamed
Schizogregarinae, and the agent of an hemolytic disease of sheep, "Amoebosporidium polyphagum Bonome 1895," which is one of the many synonyms of the piroplasm Babesia (Apicomplexa, Hematozoa). To avoid further confusion and to respect name priority, we propose the new name Paramicrosporidium for the two distinct strains, characterized herein also by molecular phylogeny.

\section{Description of Paramicrosporidium gen. nov}

Etymology: para-, Gr. prep. for beside, near; Microsporidium, representative genus of Microsporidia; Paramicrosporidium, N.L. neut., near to true Microsporidia.

MycoBank MB 807391

Formal diagnosis: Unicellular fungi, with aflagellated infective spores with chitinous wall and inactive polar filament. Intranuclear parasites of amoebae, multiplying as unwalled cells by merogony.

Latin diagnosis: Fungi unicellulares; virulentae sporae sine flagellum cum pariete definito et filo polare inerte praesentes. In nucleo amoebae parasiticae, cellulae sine pariete definito multiplicando per merogonicum stadium.

Type species: Paramicrosporidium saccamoebae

Representatives: There are at present two characterized species, with diagnosis as for the genus, identified by $18 \mathrm{~S}$ rDNA sequence (Supplementary Table 1), named based on 


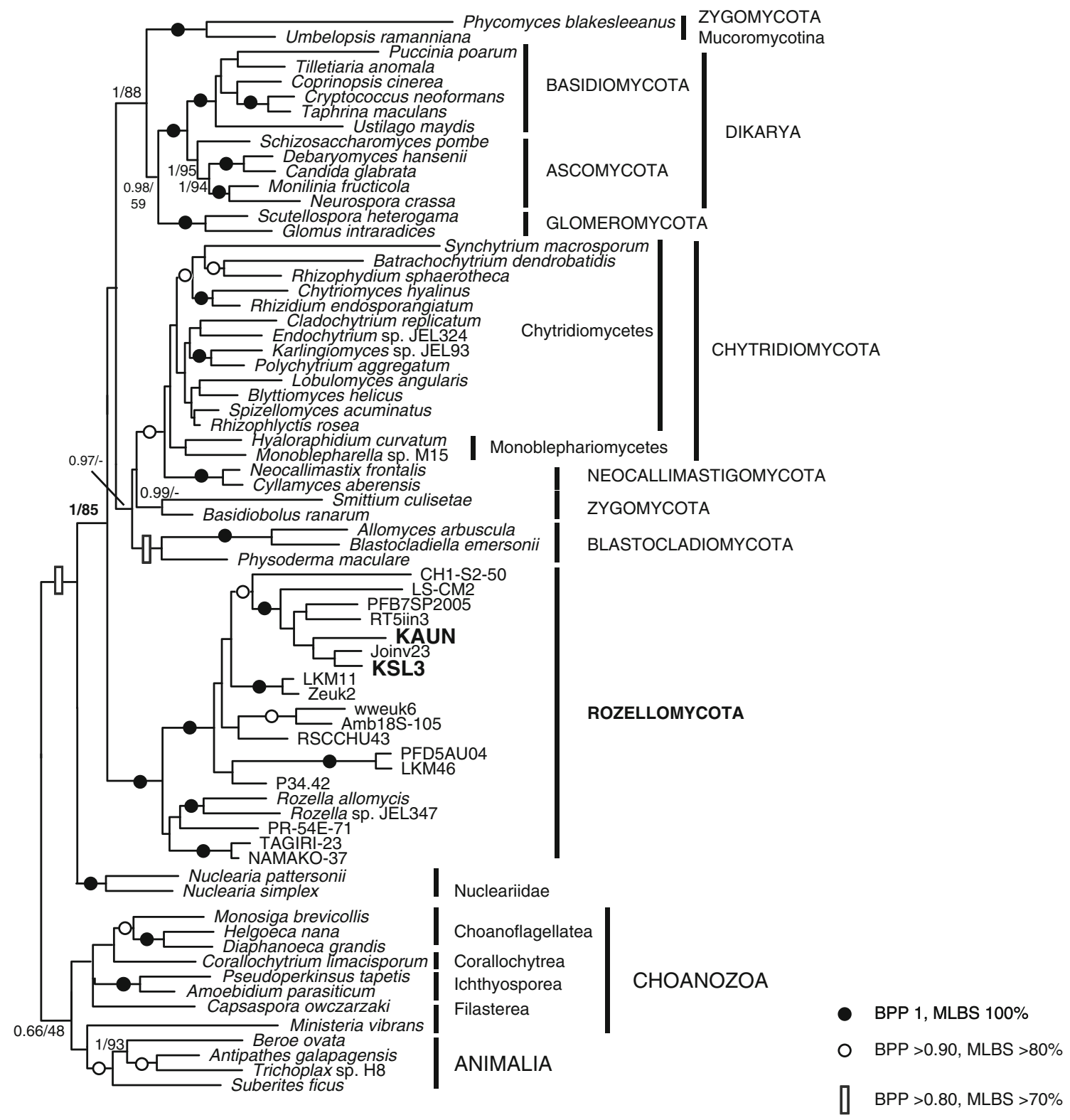

0.3

Fig. 2 18S rDNA phylogeny of Fungi, rooted on opisthokonts (Animalia and Choanozoa). Strains recovered in this study are shown in bold. Support values are indicated by symbols (see legend) as Bayesian posterior probability (BPP) and maximum likelihood bootstrap support (MLBS)

their respective amoebal hosts (see below). Other possible representatives, not yet characterized, include uncultured environmental 18S rDNA clones (e.g., Joinv23).

\section{Paramicrosporidium saccamoebae sp. nov}

Etymology: species name, Lat., of Saccamoeba. Type strain: KSL3, deposited as KSL3 (CCAP 3047/3); natural host: Saccamoeba sp. (CCAP 1572/5) (Amoebozoa, Tubulinea, Euamoebida).

MycoBank MB 807392
Formal diagnosis: Diagnosis as for the genus Paramicrosporidium. Species identified on the basis of gene sequence (18S rDNA) and natural amoebal host.

Latin diagnosis: Diagnosis ut in genere Paramicrosporidium. Species identificatur ex gene sequentia (18S rDNA) et naturalis amoeba hospite.

Paramicrosporidium vannellae sp. nov

Etymology: species name, Lat., of Vannella. Type strain: KAUN, deposited as KAUN-1 (CCAP 3047/2); natural host: 
Fig. 3 Maximum likelihood tree topology of Fungi, including Aphelidea, Rozellomycota, and the microsporidia-like strain KSL3 (in bold), and Microsporidia (branches shortened to $1 / 5$ ), based on rDNA unit (SSU+5.8S+ partial LSU). Members of opisthokonts were used as outgroup. Bootstrap values (BV) after 1,000 replicates for ML/MP/ME were indicated at nodes. Filled and open circles, node with 100 or $\geq 90 \%$ BV support with all methods, respectively; asterisk, node supported but BV $<40 \%$; dash, node not supported

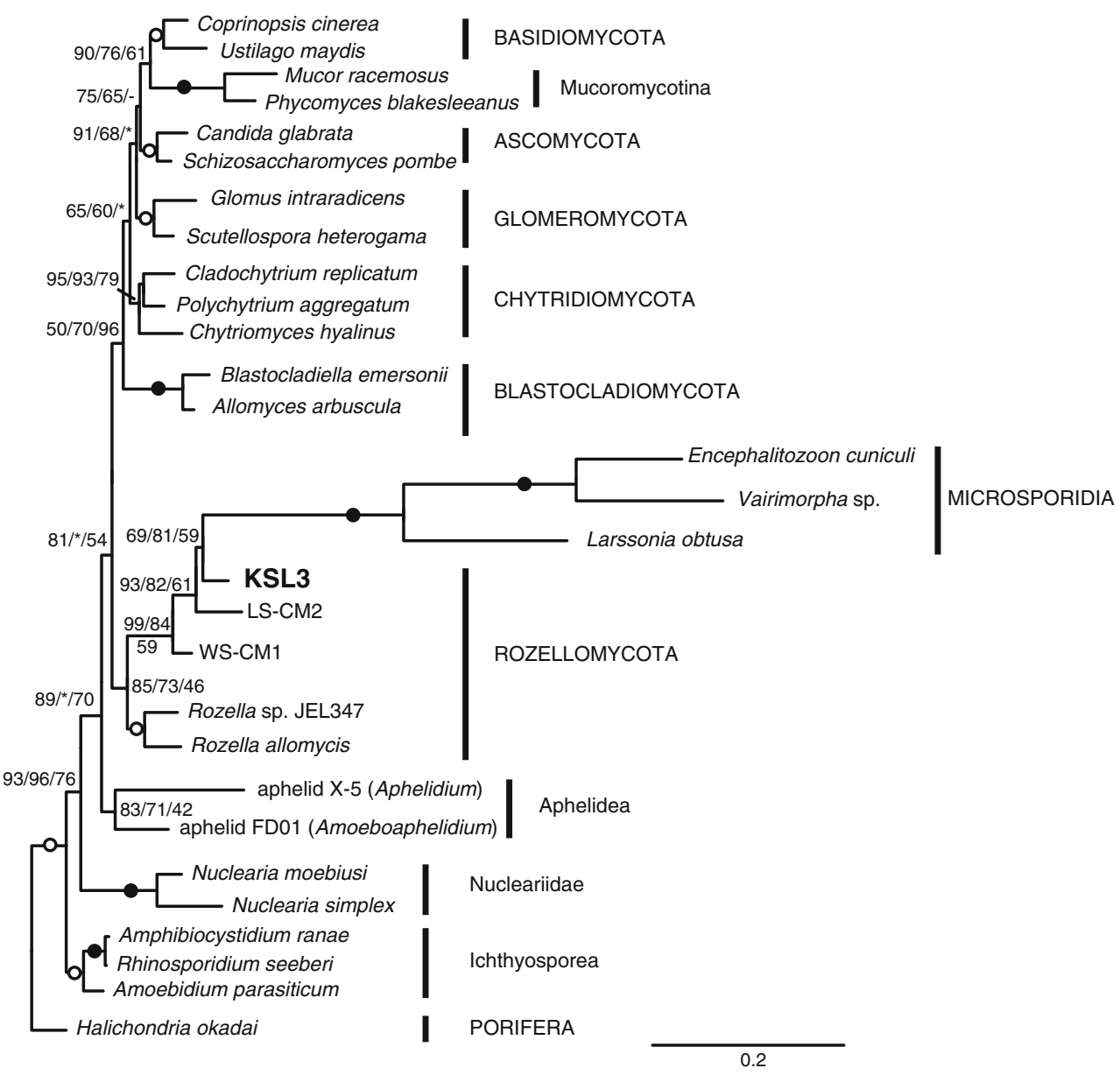

Vannella sp. (CCAP 1589/21) (Amoebozoa, Discosea, Vannellida).

MycoBank MB 807393

Formal diagnosis: Diagnosis as for the genus Paramicrosporidium. Species identified on the basis of gene sequence (18S rDNA) and natural amoebal host.

Latin diagnosis: Diagnosis ut in genere Paramicrosporidium. Species identificatur ex gene sequentia (18S rDNA) et naturalis amoeba hospite.

\section{Evolutionary considerations}

The wall-less cells evidenced for some "cryptomycotans" (Jones et al. 2011a), and the unwalled and putative (endo)phagotrophic nature of (some) Rozella spp. (Powell 1984), along with its basal position in molecular tree, have led some (Lara et al. 2010; Jones et al. 2011a) to consider the rozellid group as an intermediate form between protists and Fungi. Indeed, Fungi seem to emerge from phagotrophic opisthokont ancestors like filose amoeba Nuclearia (Steenkamp et al. 2006; Liu et al. 2009), by evolving osmotrophy (i.e., nonphagotrophic heterotrophy) having vegetative and/or spore walls of $\beta$-glucan and chitin. However, our amoebae endoparasites, which clearly emerge within the "cryptomycota," produce walled spores, and $R$. allomycis possesses fungal-specific chitin synthase genes and walled immature spores (James and Berbee 2012; James et al. 2013). Recent molecular data (Karpov et al. 2013; Letcher et al. 2013) suggested that aphelids also may belong to this group, or may be a best candidate for this putative intermediate lineage (Fig. 3; Supplementary Fig. 2). Aphelids propagate by amoeboids/ zoospores and adhere onto algal cells forming walled cysts; thus, the parasite penetrates the host cells through a germ tube, growing as phagotrophic amoeboids (Karpov et al. 2013; Letcher et al. 2013). However, most of these traits are shared with Rozella, not Microsporidia. By contrast, the unique combination of morphological and developmental traits of our endoparasites is more typical of microsporidia (Vávra and Lukeš 2013). Another molecular trait congruent with the closer position of our endoparasites with respect to Microsporidia is the progressive disappearance within the rDNA unit, of the ITS2 during evolution. Indeed, while this region measures $\sim 250-300$ base pairs in chytrids, including Rozella, it is shorter in the more derived forms like our endoparasites, disappearing completely in Microsporidia (ESM, Supplementary Table 2, Supplementary Fig. 3).

Due to the uncultured state and unknown nature of these organisms, it is likely that only wall-less stages or even wall- 
less sublineages have been detected, as recognized by Jones et al. (2011a, b). Parasitism is widespread among the various chytrid lineages, including both epicellular and intracellular adaptations to exploit different hosts. Many of the "cryptomycotan" clones originated from biotopes rich in amoebae; thus, they could potentially be amoebae parasites, more similar to our strains than to (wall-less) chytrids. For example, the clone Joinv23, which clusters with our endoparasites, is derived from amoebae-rich drinking water treatment plants (Poitelon et al. 2009).

The molecular evolutionary relationship between Rozella and Microsporidia (James and Berbee 2012; James et al. 2006a, 2013), and more recently aphelids (Karpov et al. 2013; Letcher et al. 2013), finds now also a "morphological link" with Rozellomycota through our amoebae endoparasites, which are more similar to Microsporidia than to chytrids or aphelids. Microsporidia possess proteinaceous exospores and chitin-rich endospores. Like Microsporidia, our endoparasites feed by absorption during an unwalled merogonic phase and produce nonflagellated walled spores. Adaptations to intracellular parasitism are frequently the source of evolutionary innovation (Corsaro et al. 1999). Both the formation of the penetration tube of Rozella and the activation of the polar filament of Microsporidia require initial interactions with host cells, reflecting probably a conservative infectious mechanism shared by a common ancestor (James and Berbee 2012). Recalling both chytrids and microsporidia, aphelids form a walled cyst on the host algal cell, and the parasites enter into the alga through a germ tube pushed by the posterior vacuole. Under this light, we hypothesize (Fig. 4) that distinct forms have evolved as closely related/nested lineages (ARM group) from the paraphyletic Choanozoa: from a basal chytrid-like morphotype adapted to intracellular parasitism (aphelids, Rozella), a lineage has likely developed an efficient apparatus to infect mainly somatic animal cells (Microsporidia), while other forms have conserved or lost such a function by preying on active phagotrophic amoebae (our endoparasites). The apparatus was likely lost (or never developed) in epibiont/saprotroph chytrid-like morphotypes (other "cryptomycotans").

In his recent revised classification, Cavalier-Smith (2013) maintained Microsporidia as a fungal phylum, but grouped Aphelidida and Rozellida in a new class Rozellidea, and transferred it in the phylum Choanozoa within a new subphylum Paramycia, including also Nuclearia. However, recent molecular studies strongly support the ARM clade (Karpov et al. 2013; Letcher et al. 2013), especially Rozella+ Microsporidia (James et al. 2013), and our study further confirms such a relationship. This would also imply the (unlikely) transfer of Microsporidia to Choanozoa.

Microsporidia appear to originate from highly derived endoparasitic rozellids, and both have a relationship with aphelids; however, the three groups are sufficiently different to be considered separate lineages, highlighting rather the role of paraphyletic taxa as possible ancestors (Cavalier-Smith 1998, 2013). Rozellomycota and Aphelidea could represent the borderline in the holomycotan clade, providing a new definition of Fungi. Our hypothesis (Fig. 4) should be tested ideally by phylogenomics of all these taxa, as the precise branching pattern of the three ARM group lineages is presently unclear. We provisionally propose to keep rozellids within the kingdom Fungi, with an emended description as Rozellomycota (see below), as well as Microsporidia, suggesting further phylogenomics studies to determine whether the boundary among Fungi and Paramycia lies between aphelids and Rozellomycota or between aphelids and nucleariids.

Need for emendation: proposal of Rozellomycota phylum novum

Jones et al. (2011b) defined the Cryptomycota as mainly epibiontic unicellular chytrid-like unwalled organisms, considering both endoparasitism and morphology of Rozella as exceptional, and arguing that the "cryptic" nature of the group could be a higher rank taxonomic descriptor. Nevertheless, new data on Rozella (James and Berbee 2012; James et al. 2013) and our own results reported herein indicate that emendation is needed. First, the presence of wall-less forms in distinct fungal lineages suggests that this trait appeared more likely by secondary loss. Secondly, lifestyles in this clade are practically unknown. Epibiontic cells with intracellular rhizoids are reported from other chytrids, including algal parasites with wall-less stages (Ustinova et al. 2000; Hoffman et al. 2008). Moreover, Rozella and the amoebae endoparasites are genetically distant and morphologically very different; thus, it is likely that other forms of endoparasitism may exist in this group. This clearly indicates incomplete description of "Cryptomycota." Thirdly, we provide now also morphological evidence (amoebae endoparasites) to complete previous molecular phylogenetic ones (Rozella, aphelids), all showing an evolutionary link with Microsporidia. These three lineages form a clade, the socalled ARM group, which comprise organisms with fungallike walls. Our endoparasites emerge within rozellids with aphelids as the most basal lineage in 18S rDNA trees (Fig. 2; Supplementary Fig. 2) and as sister to Microsporidia within a larger clade comprising Rozella but not aphelids in rDNA unit tree (Fig. 3). Finally, Jones et al. emphasized the presumed nonrepresentative status of Rozella, arguing that highest ranks like phyla should be named not on the basis of included genera, but rather on some special characteristic, thus they create the name Cryptomycota to "... highlight the cryptic nature... hidden from science until revealed by molecular methods...". However, such a "cryptic" nature revealed by molecular methods could apply to many other eukaryotic lineages, like for example the Archaeorhizomycetes (Rosling et al. 2011) among fungi, or new marine picoplankton groups (LópezGarcía et al. 2001; Not et al. 2007), as well as to most 


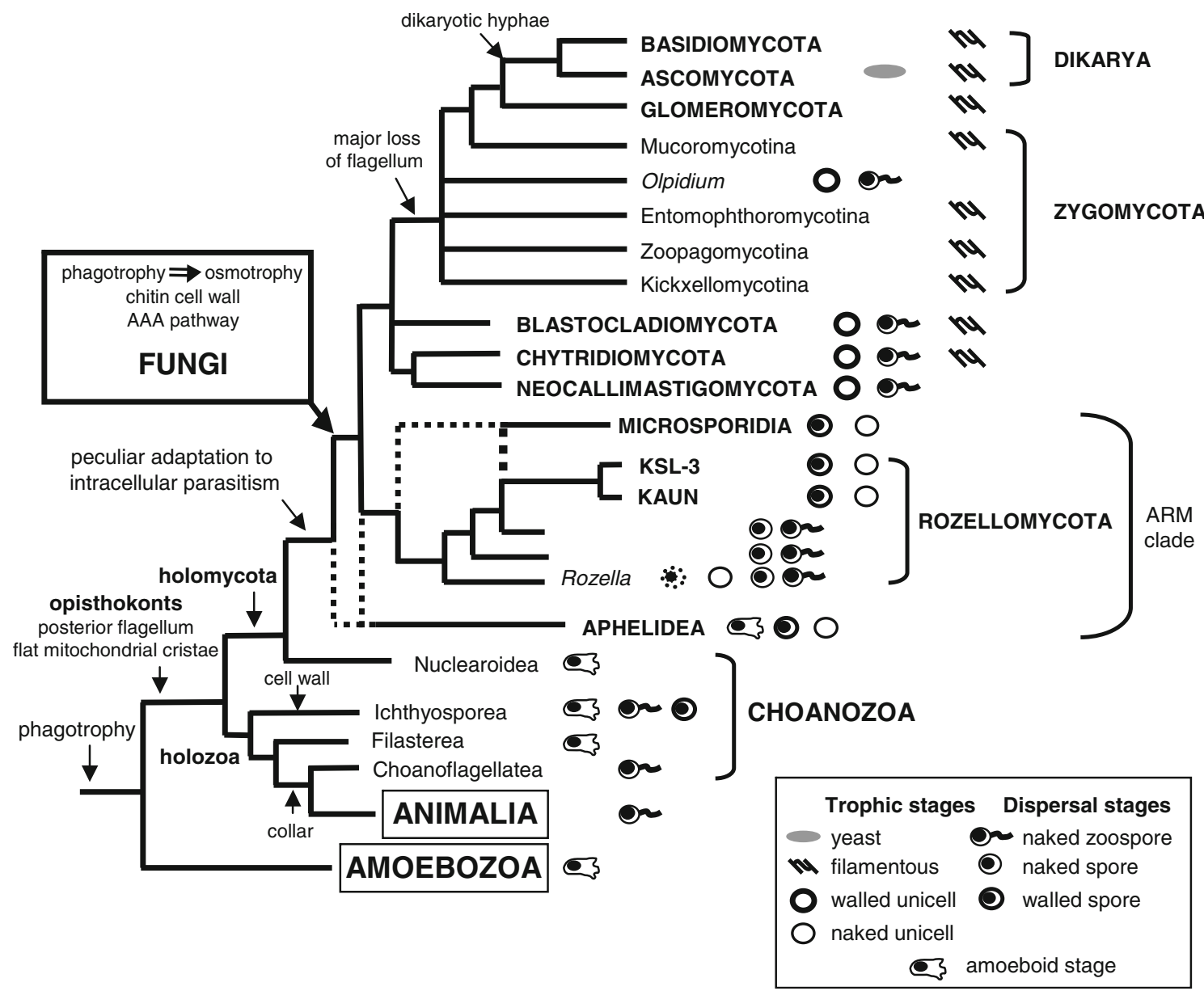

Fig. 4 Diagram of the major evolutionary steps in the opisthokonts. From the paraphyletic Choanozoa originated separately animals (clade holozoa) and fungi (clade holomycota). Fungi are classically defined as nonphagotrophic absorptive organisms with chitin cell wall in some stages of their life cycle. The flagellate motile cell (zoospore) is basal in their early radiation and successively lost with the development of filamentous forms. Wall-less trophic stages, present in some parasitic fungi,

prokaryotic lineages, reflecting technical advances rather than a diagnostic feature for a taxon.

In order to rationalize taxonomy and to minimize confusion, a previous effort was made to propose higher level classification of Fungi based on a typified genus (Hibbett et al. 2007). According to this proposal, all recognized chytrid phyla were named from their first typified genus, as well as major lineages of "zygomycota." Furthermore, as previously underlined (James and Berbee 2012), the name "Cryptomycota" would be confusing since this refers to an incompletely described chytrid phylum and to the already established ascomycete genus Cryptomyces. Considering Rozella as a typical member, and the first typified genus of this group, and following previous suggestions (Hibbett et al. 2007; James and Berbee 2012), we propose to adopt the name Rozellomycota, for an emended Cryptomycota/Rozellida.

It should be noted that, during the revision of our manuscript, Doweld published in Index Fungorum, no. 43, "Rozellomycota characterize also members of the ARM clade. However, walled spores are present in both Rozella and in our strains (in bold), as well as in Microsporidia. The adaptation to intracellular parasitism seems to be at the origin of the ARM clade, Rozellomycota and Microsporidia possibly representing an early chytrid lineage. Aphelids, carrying more intermediate features, could represent an earlier lineage in the holomycotan clade towards the emergence of Fungi

phylum novum" (IF550328). However, in our opinion, this description is wrong. Indeed, Doweld clearly did not consider the great diversity of the phylum (Lara et al. 2010; Jones et al. 2011a, b; James and Berbee 2012), as he surprisingly provides a description limited to obligate intracellular parasites, i.e., Rozella species alone, excluding thus epibiontic "cryptomycotans" (Jones et al. 2011a). Therefore, the description of Doweld would fit, at best, as diagnostic for a lower level taxon, e.g., family or even genus, but surely not for the entire phylum.

\section{Taxonomy}

\section{Kingdom Fungi}

Rozellomycota (James and Berbee 2012) D. Corsaro \& R. Michel, phylum novum emend. 
(synonyms: Cryptomycota Jones \& Richards 2011, pro parte, "Rozellida," Lara et al. 2010)

\section{MycoBank MB807390}

Etymology: Rozello- from Rozella, a first typified described genus; -mycota, Gr. for fungi, ending for a fungal phylum.

\section{Type genus: Rozella Cornu 1872}

Other representatives: epibiontic chytrid-like "cryptomycotans" (Jones et al. 2011a), amoebae endoparasites Paramicrosporidium spp. (this study).

Formal diagnosis: Unicellular fungi, with uniflagellated zoospores or aflagellated infective spores; cysts and resting spores. Cells wall-less or with chitinous wall. Both intracellular parasitic and epibiotic forms described.

Latin diagnosis: Fungi unicellulares, cum uniflagellatae zoosporae aut virulentae sporae sine flagellum; kystes et sporae perdurantes praesentes. Cellulae sine vel cum pariete definito. Intracellularis parasiticae et epibioticae formae describitur.

Acknowledgments We thank B. Hauröder and E.N. Schmid for assistance and previous electron microscopy data. This study was supported by internal fundings of each laboratory.

\section{References}

Canning EU, Vávra J (2000) Phylum Microsporidia Balbiani, 1882. In: Lee JJ, Leedale GF, Bradbury P (eds) The illustrated guide to the protozoa. Allen Press, Lawrence, pp 39-126

Capella-Gutiérrez S, Marcet-Houben M, Gabaldón T (2012) Phylogenomics supports microsporidia as the earliest diverging clade of sequenced fungi. BMC Biol 10:47

Cavalier-Smith T (1998) A revised six-kingdom system of life. Biol Rev Camb Philos Soc 73:203-266

Cavalier-Smith T (2013) Early evolution of eukaryote feeding modes, cell structural diversity, and classification of the protozoan phyla Loukozoa, Sulcozoa, and Choanozoa. Eur J Protistol 49:115-178

Corradi N, Keeling PJ (2009) Microsporidia: a journey through radical taxonomical revisions. Fungal Biol Rev 23:1-8

Corsaro D, Venditti D, Padula M, Valassina M (1999) Intracellular life. Crit Rev Microbiol 25:39-79

Corsaro D, Müller K-D, Wingender J, Michel R (2013) 'Candidatus Mesochlamydia elodeae' (Chlamydiae: Parachlamydiaceae), a novel chlamydia parasite of free-living amoebae. Parasitol Res 112:829-838

Didier ES, Weiss LM (2011) Microsporidiosis: not just in AIDS patients. Curr Opin Infect Dis 24:490-495

Foissner I, Foissner W (2005) Ciliatosporidium platyophryae nov. gen., nov. spec. (Microspora incerta sedis), a parasite of Platyophrya terricola (Ciliophora, Colpodea). Eur J Protistol 31:248-259

Fokin SI, Di Giuseppe G, Erra F, Dini F (2008) Euplotespora binucleata n. gen., n. sp. (Protozoa: Microsporidia), a parasite infecting the hypotrichous ciliate Euplotes woodruffi, with observations on microsporidian infections in Ciliophora. J Eukaryot Microbiol 55: 214-228

Franzen C (2004) Microsporidia: how can they invade other cells. Trends Parasitol 20:275-279
Held AA (1981) Rozella and Rozellopsis: naked endoparasitic fungi which dress-up as their hosts. Bot Rev 47:451-515

Hibbett DS, Binder M, Bischoff JF, Blackwell M, Cannon PF, Eriksson OE, Huhndorf S, James TY, Kirk PM, Lücking R, Thorsten Lumbsch H, Lutzoni F, Matheny PB, McLaughlin DJ, Powell MJ, Redhead S, Schoch CL, Spatafora JW, Stalpers JA, Vilgalys R, Aime MC, Aptroot A, Bauer R, Begerow D, Benny GL, Castlebury LA, Crous PW, Dai Y-C, Gams W, Geiser DM, Griffith GW, Gueidan C, Hawksworth DL, Hestmark G, Hosaka K, Humber RA, Hyde KD, Ironside JE, Kõljalg U, Kurtzman CP, Larsson K-H, Lichtwardt R, Longcore J, Miądlikowska J, Miller A, Moncalvo J-M, Mozley-Standridge S, Oberwinkler F, Parmasto E, Reeb V, Rogers JD, Roux C, Ryvarden L, Sampaio JP, Schüssler A, Sugiyama J, Thorn RG, Tibell L, Untereiner WA, Walker C, Wang Z, Weir A, Weiss M, White MM, Winka K, Yao YJ, Zhang N (2007) A higher-level phylogenetic classification of the Fungi. Mycol Res 111:509-547

Hoffman Y, Aflalo C, Zarka A, Gutman J, James TY, Boussiba S (2008) Isolation and characterization of a novel chytrid species (phylum Blastocladiomycota), parasitic on the green alga Haematococcus. Mycol Res 112:70-81

Hoffmann R, Michel R, Schmid EN, Müller K-D (1998) Natural infection with microsporidian organisms (KW19) in Vannella sp. (Gymnamoebia) isolated from a domestic tap-water supply. Parasitol Res 84:164-166

James TY, Berbee ML (2012) No jacket required - new fungal lineage defies dress code: recently described zoosporic fungi lack a cell wall during trophic phase. Bioessays 34:94-102

James TY, Kauff F, Schoch CL, Matheny PB, Hofstetter V, Cox CJ, Celio G, Gueidan C, Fraker E, Miadlikowska J, Lumbsch HT, Rauhut A, Reeb V, Arnold AE, Amtoft A, Stajich JE, Hosaka K, Sung GH, Johnson D, O'Rourke B, Crockett M, Binder M, Curtis JM, Slot JC, Wang Z, Wilson AW, Schüssler A, Longcore JE, O'Donnell K, Mozley-Standridge S, Porter D, Letcher PM, Powell MJ, Taylor JW, White MM, Griffith GW, Davies DR, Humber RA, Morton JB, Sugiyama J, Rossman AY, Rogers JD, Pfister DH, Hewitt D, Hansen K, Hambleton S, Shoemaker RA, Kohlmeyer J, VolkmannKohlmeyer B, Spotts RA, Serdani M, Crous PW, Hughes KW, Matsuura $\mathrm{K}$, Langer E, Langer $\mathrm{G}$, Untereiner WA, Lücking R, Büdel B, Geiser DM, Aptroot A, Diederich P, Schmitt I, Schultz M, Yahr R, Hibbett DS, Lutzoni F, McLaughlin DJ, Spatafora JW, Vilgalys R (2006a) Reconstructing the early evolution of Fungi using a six-gene phylogeny. Nature 443:818-822

James TY, Letcher PM, Longcore JE, Mozley-Standridge PD, Powell MJ, Griffith GW, Vilgalys R (2006b) A molecular phylogeny of the flagellated fungi (Chytridiomycota) and description of a new phylum (Blastocladiomycota). Mycologia 98:860-871

James TY, Pelin A, Bonen L, Ahrendt S, Sain D, Corradi N, Stajich JE (2013) Shared signatures of parasitism and phylogenomics unite Cryptomycota and Microsporidia. Curr Biol 23:1548-1553

Jobb G, von Haeseler A, Strimmer K (2004) TREEFINDER: a powerful graphical analysis environment for molecular phylogenetics. BMC Evol Biol 4:18

Jones MDM, Forn I, Gadelha C, Egan MJ, Bass D, Massana R, Richards TA (2011a) Discovery of novel intermediate forms redefines the fungal tree of life. Nature 474:200-203

Jones MDM, Richards TA, Hawksworth DL, Bass D (2011b) Validation and justification of the phylum name Cryptomycota phyl. nov. IMA Fungus 2:173-175

Karpov SA, Mikhailov KV, Mirzaeva GS, Mirabdullaev IM, Mamkaeva KA, Titova NN, Aleoshin VV (2013) Obligately phagotrophic aphelids turned out to branch with the earliest-diverging fungi. Protist 164:195-205

Koestler T, Ebersberger I (2011) Zygomycetes, Microsporidia, and the evolutionary ancestry of sex determination. Genome Biol Evol 3: 186-194 
Lara E, Moreira D, López-García P (2010) The environmental clade LKM11 and Rozella form the deepest branching clade of Fungi. Protist 161:116-121

Larsson JIR, Køie M (2006) The ultrastructure and reproduction of Amphiamblys capitellides (Microspora, Metchnikovellidae), a parasite of the gregarine Ancora sagittata (Apicomplexa, Lecudinidae), with redescription of the species and comments on the taxonomy. Eur J Protistol 42:233-248

Letcher PM, Lopez S, Schmieder R, Lee PA, Behnke C, Powell MJ, McBride RC (2013) Characterization of Amoeboaphelidium protococcarum, an algal parasite new to the cryptomycota isolated from an outdoor algal pond used for the production of biofuel. PLoS ONE 8:e56232

Liu Y, Steenkamp ET, Brinkmann H, Forget L, Philippe H, Lang BF (2009) Phylogenomic analyses predict sistergroup relationship of nucleariids and Fungi and paraphyly of zygomycetes with significant support. BMC Evol Biol 9:272

López-García P, Rodríguez-Valera F, Pedrós-Alió C, Moreira D (2001) Unexpected diversity of small eukaryotes in deep-sea Antarctic plankton. Nature 409:603-607

Michel R, Schmid EN, Böker T, Hager DG, Müller K-D, Hoffmann R, Seitz HM (2000) Vannella sp. harboring Microsporidia-like organisms isolated from the contact lens and inflamed eye of a female keratitis patient. Parasitol Res 86:514-520

Michel R, Müller K-D, Hauröder B (2009) A novel microsporidian endoparasite replicating within the nucleus of Saccamoeba limax isolated from a pond. Endocytobios Cell Res 19:120-126

Michel R, Müller K-D, Schmid EN, Theegarten NN, Hauröder B, Corsaro D (2012) Isolation of Thecamoeba terricola from bark of Platanus occidentalis harbouring spore-forming eukaryotic endoparasites with intranuclear development. Endocytobios Cell Res 22: $37-42$

Not F, Valentin K, Romari K, Lovejoy C, Massana R, Töbe K, Vaulot D, Medlin LK (2007) Picobiliphytes: a marine picoplanktonic algal group with unknown affinities to other eukaryotes. Science 315: 253-255

Poitelon J-B, Joyeux M, Welté B, Duguet J-P, Peplies J, DuBow MS (2009) Identification and phylogeny of eukaryotic 18S rDNA phylotypes detected in chlorinated finished drinking water samples from three Parisian surface water treatment plants. Lett Appl Microbiol 49:589-595

Powell MJ (1984) Fine structure of the unwalled thallus of Rozella polyphagi in its host Polyphagus euglenae. Mycologia 76:10391048

Ronquist F, Huelsenbeck JP (2003) MrBayes 3: Bayesian phylogenetic inference under mixed models. Bioinformatics 19:1572-1574

Rosling A, Cox F, Cruz-Martinez K, Ihrmark K, Grelet G-A, Lindahl BD, Menkis A, James TY (2011) Archaeorhizomycetes: unearthing an ancient class of ubiquitous soil fungi. Science 333:876-879

Scheid P (2007) Mechanism of intrusion of a microsporidian-like organism into the nucleus of host amoebae (Vannella sp.) isolated from a keratitis patient. Parasitol Res 101:1097-1102

Shalchian-Tabrizi K, Minge MA, Espelund M, Orr R, Ruden T, Jakobsen KS, Cavalier-Smith T (2008) Multigene phylogeny of choanozoa and the origin of animals. PLoS One 3:e2098

Sokolova YY, Paskerova GG, Rotari YM, Nassonova ES, Smirnov AV (2013) Fine structure of Metchnikovella incurvata Caullery and Mesnil 1914 (Microsporidia), a hyperparasite of gregarines Polyrhabdina sp. from the polychaete Pygospio elegans. Parasitology 140:855-867

Sprague V (1977) Classification and phylogeny. In: Bulla LA, Cheng TC (eds) Comparative pathobiology, vol 2, Systematics of the Microsporidia. Plenum Press, New York, pp 1-30

Steenkamp ET, Wright J, Baldauf SL (2006) The protistan origins of Animals and Fungi. Mol Biol Evol 23:93-106

Tamura K, Peterson D, Peterson N, Stecher G, Nei M, Kumar S (2011) MEGA5: molecular evolutionary genetics analysis using maximum likelihood, evolutionary distance, and maximum parsimony methods. Mol Biol Evol 28:2731-2739

Torres-Machorro AL, Hernández R, Cevallos AM, López-Villaseñor I (2010) Ribosomal RNA genes in eukaryotic microorganisms: witnesses of phylogeny? FEMS Microbiol Rev 34:59-86

Ustinova I, Krienitz L, Huss VAR (2000) Hyaloraphidium curvatum is not a green alga, but a lower fungus; Amoebidium parasiticum is not a fungus, but a member of the DRIPs. Protist 151:253-262

Vávra J, Lukeš J (2013) Microsporidia and 'the art of living together'. In: Rollinson D (ed) Advances in parasitology, Academic Press, vol. 82, chap. 4, pp 253-320. 